\title{
UM ANTROPÓLOGO NA EDUCAÇÃO
}

\author{
Amurabi Oliveira ${ }^{1}$
}

Resumo: A biografia não deve ser entendida como uma sucessão de fatos completamente singulares e aleatórios, uma vez que, por meio dela, podemos ter acesso a questões mais amplas que tangenciam as experiências sociais narradas; mais que isso, a análise biográfica nos permite reconhecer a indissociabilidade entre indivíduo e sociedade, entendidos aqui não como polos opostos. Através da narrativa de meu próprio percurso enquanto antropólogo na educação, proponho-me a desenvolver uma reflexão em torno do campo da Antropologia da Educação no Brasil, o qual compreendo está ainda em formação, ocupando um lugar periférico na agenda de pesquisas da Antropologia brasileira, indicando algumas tensões existentes e a necessidade de engajamento de antropólogos nessa discussão, e de pesquisadores com formação em educação, mas que reconhecem a relevância das discussões antropológicas para a educação. Além de destacar os percalços encontrados no processo de inserção no campo educacional, almejo elucidar questões que entendo serem pertinentes para se compreender a relação entre a Antropologia e a Educação, apontando elementos que nos possibilitem pensar em que a ciência antropológica pode contribuir para a pesquisa em educação, bem como para a formação de professores, partindo do pressuposto que a Antropologia constitui um dos "fundamentos teóricos da educação".

Palavras-Chave: Educação. Antropologia educacional. Biografia.

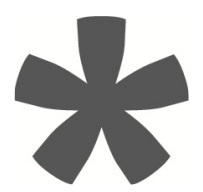

1 Licenciado e Mestre em Ciências Sociais (UFCG), Doutor em Sociologia (UFPE). Professor da Universidade Federal Santa Catarina (UFSC) Pesquisador do CNPQ, membro da Comissão de Educação e Tecnologia da Associação Brasileira de Antropologia (ABA). E-mail: amurabi_cs@hotmail.com 
AN ANTHROPOLOGIST ON EDUCATION

Abstract: Biography should not be understood as a succession of completely natural and random facts, since, through it, we can have access to broader issues that touch narrated social experiences; more than that, the biographical analysis allows us to recognize the inseparability between individual and society, here understood not as opposite poles. Through the narrative of my own journey as an anthropologist in education, I propose to develop a reflection on the field of Education Anthropology in Brazil, which I understand is still in formation, occupying a secondary role in the research agenda of the Brazilian anthropology, indicating some tensions and the need for engagement of anthropologists in this discussion, and of researchers with a background in education, but who recognize the relevance of anthropological discussions for education. In addition to highlighting the pitfalls encountered in the integration process in the educational field, I aim to elucidate relevant issues to understanding the relationship between anthropology and education, highlighting elements that allow us to think that anthropological science can contribute to research in education as well as to teacher training, on the assumption that anthropology is one of the "theoretical foundations of education".

Keywords: Education. Educational anthropology. Biography.

\section{UN ANTROPÓLOGO EN LA EDUCACIÓN}

Resumen: La biografía no debe entenderse como una sucesión de hechos totalmente naturales y al azar, ya que a través de ella podemos acceder a los temas más amplios que están relacionados con las experiencias sociales narradas, más que eso, el análisis biográfico nos permite reconocer la inseparabilidad entre el individuo y la sociedad, aquí entendida no como polos opuestos. A través de la narración de mi propio viaje como antropólogo en la educación, me propongo desarrollar una reflexión sobre el campo de la antropología la educación en el Brasil, el cual entiendo que está todavía en formación, ocupando un papel secundario en la agenda de investigación de la antropología brasileña, indicando algunas tensiones y la necesidad de participación de los antropólogos en esta discusión, e investigadores con graduación en educación, pero que reconocen la importancia de las discusiones antropológicas para la educación. Además de destacar las dificultades encontradas en el proceso de integración en el ámbito educativo, mi objetivo es dilucidar cuestiones que entiendo son relevantes para la comprensión de la relación entre la antropología y la educación, destacando los elementos que nos permitan pensar en que la ciencia antropológica puede contribuir a la investigación la educación, así como para la formación del profesorado, en el supuesto de que la antropología es uno de los "fundamentos teóricos de la educación."

Palabras clave: Educación. Antropología de la educación. Biografía. 


\section{Introdução}

Pretendo, por meio deste artigo, realizar uma reflexão sobre o lugar da Antropologia no campo educacional, o que buscarei desenvolver possuindo como fio condutor minha própria trajetória enquanto antropólogo que tem se dedicado a essa seara; contudo, faz-se necessário, primeiramente, debater com mais afinco sobre a formulação da Antropologia da Educação, especialmente no cenário brasileiro.

Gusmão (1997) nos traz uma reflexão instigante sobre os diálogos possíveis entre a Antropologia e a Educação, indicando que, apesar de soar como uma novidade no Brasil, os estudos de comunidade nos anos de 1970 remetiam a um período anterior, sendo uma figura fulcral na gênese dessa discussão Franz Boas (1858-1942) - bem como suas discípulas Margaret Mead (1901-1978) e Ruth Benedict (1887-1948) -, que se engajou ativamente nas discussões educacionais de seu tempo, ainda que pouco se conheça dessa questão na Antropologia brasileira.

A autora ainda indica que há uma necessidade de superar a dicotomia que tem se construído, que tende a pensar a Educação no polo da prática e a Antropologia no da teoria. Em termos históricos, podemos realizar um recuo ainda maior no tempo, ao nos referirmos ao surgimento da Antropologia Pedagógica junto aos cursos de formação de professores nas primeiras décadas do século XX no Brasil, nas chamadas Escolas Normais (OLIVEIRA, 2013c), ainda que essa Antropologia tenha sido claramente assentada numa perspectiva biológica, influenciada por autores como Lombroso, mas que, em todo o caso, representou uma revolução intelectual em tais cursos.

A questão não é encontrar a origem específica desse diálogo, datando-o, até mesmo porque uma preocupação com a infância, e com os processos de aprendizagem, pode-se dizer, sempre se fez presente na Antropologia de alguma forma desde a sua gênese (ROCHA; TOSTA, 2008). Importa aqui situar a discussão, indicando que não se trata de algo completamente novo no campo antropológico.

O advento do modelo universitário, e posteriormente as mudanças vivenciadas nele, implicaram na delineação de temáticas prioritárias na Antropologia brasileira (PEIRANO, 1981), que constituiu sua agenda de 
pesquisa distante, de maneira substancial, da questão educacional, o que se aprofunda com a Reforma Universitária de 1968, quando ocorre o advento das Faculdades de Educação, que passam a concentrar tais discussões.

As Faculdades de Educação, que foi onde construí minha carreira na Antropologia da Educação, passam a se desenvolver um profícuo debate sobre os mais variados temas que recorrem a conceitos da Antropologia, em especial o de Cultura, e a procedimentos metodológicos, com destaque para a Etnografia, ainda que isso não se dê sem sobressaltos, como nos indica Valente (1996), difundindo-se uma leitura particular dessa proposta metodológica, representada principalmente pelo trabalho de André (1995).

Essa formação singular da Antropologia da Educação parece que tendeu a produzir uma "Antropologia sem Antropólogos", na medida em que se popularizou uma "antropologização" da educação, sem que, com isso, houvesse, de fato, uma apropriação substancial das categorias e teorias Antropológicas; nesse processo, a etnografia viu-se transformada em “técnica”, e a Cultura tornou-se um conceito reificado e estático.

Não quero dizer, com isso, que não haja antropólogos engajados no campo da educação ou mesmo bons pesquisadores com formação em educação que se apropriaram devidamente da Antropologia, mas estes casos são a exceção, não a regra.

Ainda que o debate educacional tenha ganhado espaço nos últimos anos junto à Antropologia Brasileira, como podemos observar por meio do incremento de Grupos de Trabalho junto a eventos, como a Reunião Brasileira de Antropologia (GUSMÃO, 2009), este ainda é um tema marginal, e como pesquisador de tal temática quero agora situar minha trajetória de pesquisador também marginal no campo da Antropologia, ao me dedicar à Educação.

\section{Uma Trajetória não Linear}

Como tantos outros percursos acadêmicos, o meu não foi isento de rupturas, ainda que me pareça mais linear e coerente que o da maioria. Geertz (2001), por exemplo - o antropólogo que causou maior impacto na minha formação certamente -, afirma que teve uma vida improvisada e, de 
fato, quando narra sua carreira, a impressão que fica é que Geertz só se tornou Geertz por uma série de acasos.

Vindo de uma família de classe média e tendo estudado em uma escola tradicional, ser professor não parecia a opção mais óbvia para mim; no entanto, lembro-me de que aos 13 anos já havia realizado essa escolha e, como pendia entre a história e a geografia, resolvi que no vestibular não deveria optar por nem uma e nem outra, mas, sim, pelo curso de Ciências Sociais, que, pelo que havia lido na descrição presente no "manual do candidato", era a licenciatura mais abrangente na área de Ciências Humanas. Como minha família esperava que eu fizesse direito, essa minha escolha não se deu sem o devido drama.

Ao adentrar no curso de Ciências Sociais, fiquei fascinado, e já no início havia três grandes caminhos que poderia seguir, representados pela Antropologia, Sociologia e Ciência Política; a Antropologia me fascinou desde o princípio, lembro-me do primeiro texto: "Relativizando", do Roberto DaMatta, e ao lê-lo recordo-me que naquele momento pensei que eu deveria oportunizar aos meus futuros alunos a mesma sensação de descoberta do mundo que senti.

Em verdade, como é recorrente nos cursos de Ciências Sociais (mas não só neles), a licenciatura era percebida como algo menor, mais ainda considerando que os licenciados não poderiam ser sociólogos, segundo a legislação vigente (MORAES, 2003), e a estrutura curricular do curso refletia essa realidade: "Trata-se de uma licenciatura inspirada em um curso de bacharelado, em que o ensino do conteúdo específico prevalece sobre o pedagógico e a formação prática assume, por sua vez, um papel secundário" (PEREIRA, 1999, p. 113).

As disciplinas denominadas pedagógicas eram muito mal vistas, eram percebidas como uma perda de tempo pela maior parte dos alunos do curso, e fazer a licenciatura era a opção daqueles que "não gostavam de estudar". Eu, particularmente, era visto como um ponto fora da curva, de tal modo que certa vez uma professora (de Antropologia) disse-me que eu não tinha o perfil da licenciatura, o que supostamente seria um elogio. 
Procurei me engajar em programas que me possibilitassem a vivência da docência, então me tornei professor voluntário em um cursinho pré-vestibular para alunos oriundos de escolas públicas, lecionando geografia e, posteriormente, história; depois passei a ser monitor de Introdução à Sociologia e depois Teoria Sociológica Clássica, no curso de Ciências Sociais, o que também eram atividades percebidas como menores, ao menos em comparação com aqueles que se tornavam alunos de iniciação científica, que seriam os "iniciados", como nos dizem Nogueira e Canaan (2009). Ironicamente, nunca fui monitor de Antropologia, por dois motivos: horários e afinidades com os professores que lecionavam as disciplinas com inscrições abertas naquele momento.

A opção pela licenciatura não me pareceu tão problemática, tampouco minha paixão pelo ensino enquanto uma questão própria, ao menos até a aproximação do final do curso, quando deveria escolher que rumo seguir; apesar de já trabalhar como professor naquele momento, ingressar em uma pós-graduação pareceu-me o melhor caminho, pois sentia lacunas profundas que talvez o ensino pós-graduado pudesse suprimir.

Realizei três seleções, em programas e universidades distintos: Antropologia, Ciências Sociais e Sociologia, e, como em nenhum deles havia pesquisadores que pudessem me orientar no campo educacional, segui com um projeto que abarcava minha outra paixão intelectual: o universo religioso. Entra aí um ponto que merece atenção: a ausência de pesquisadores na Antropologia (e também na Sociologia) voltados para a pesquisa educacional presentes em Programas de Pós-Graduação na área de Ciências Sociais, de tal modo que ainda é um desafio fazer com que essa discussão se torne presente nesse espaço, compreendido como locus fundamental da legitimação acadêmica.

Ao término das seleções, havia sido aprovado nos três programas; optei por permanecer na mesma Universidade em que me graduei, ingressando no Programa de Pós-Graduação em Ciências Sociais, o que também me fez adiar uma decisão que emergiu durante minha graduação: Antropologia ou Sociologia? Pouco após meu ingresso, fui aprovado na seleção de professor substituto de Ciência Política, porém achei melhor não assumir, por uma série 
de motivos, mas o principal estava relacionado a meu tênue, ou quase inexistente, interesse pela área.

Prosseguir na Pós-Graduação me fez abrir os horizontes, mas, ainda tendo um objeto de pesquisa claramente situado, no campo da Religião, mantive meus estudos sobre educação, por compreender tal feito como fundamental para qualquer professor, e foi a partir daquele momento que ficou mais evidente para mim o quanto a reflexão antropológica se fazia fundamental para a prática docente, em especial a partir da ideia de alteridade. Segundo Gusmão (2003, p. 87),

A alteridade revela-se no fato de que o que eu sou e o outro é não se faz de modo linear e único, porém constitui um jogo de imagens múltiplo e diverso. Saber o que eu sou e o que o outro é depende de quem eu sou, do que acredito que sou, com quem vivo e por quê. Depende também das considerações que o outro tem sobre isso, a respeito de si mesmo, pois é nesse processo que cada um se faz pessoa e sujeito, membro de um grupo, de uma cultura e de uma sociedade. Depende também do lugar a partir do qual nós nos olhamos. Trata-se de processos decorrentes de processos culturais que nos formam e informam, deles resultando nossa compreensão do mundo e nossas práticas frente ao igual e ao diferente.

Pensar alteridade me levava à conclusão de que ler Antropologia não deveria ser um exercício exclusivo dos licenciados em Ciências Sociais; para mim ficava cada vez mais claro que ser professor era uma verdadeira “aventura antropológica” e, rememorando as disciplinas pedagógicas que havia cursado, percebi que a Antropologia era esquecida, fala-se de Sociologia da Educação, Filosofia da Educação, História da Educação, Psicologia da Educação, Políticas da Educação, mas a Antropologia continuava como uma intrusa no debate educacional.

No período do Mestrado, tornei-me ainda professor substituto na Universidade Estadual da Paraíba no campus de Patos-PB, e, mesmo sendo uma seleção para Sociologia, apenas duas turmas eram de Sociologia, as demais eram disciplinas vinculadas à educação; vi aí a oportunidade de inserir reflexões antropológicas na educação, o que deu incrivelmente certo. Mesmo se tratando de cursos de exatas (licenciaturas em ciências e em computação), a receptividade foi significativa. A ideia que me norteava naquele momento 
aproximava-se com as intenções apontadas por Dauster (2007) acerca do ensino de Antropologia para cursos de formação de professores, pois acredito ser fundamental para um docente desenvolver a capacidade de perceber a heterogeneidade social e cultural existente no ambiente escolar.

Passei pouco tempo na condição de professor substituto, logo depois me efetivei na rede federal de educação profissional e tecnológica no então CEFET Petrolina, onde passei a lidar com um público mais amplo, atuando no Ensino Médio, nos cursos superiores em tecnologia e nas licenciaturas em exatas. Apesar de ser concursado para Sociologia, e amar tal disciplina, sempre me causava um incomodo ao saber que apenas ela, do leque das Ciências Sociais, se fazia presente nos cursos de formação de professores, e ainda assim de forma bastante pontual. Segui antropologizando meu programa de Sociologia, ampliando as discussões sobre cultura e educação para além do debate em torno do capital cultural, tal como proposto por Bourdieu, ainda que esse seja o sociológico que mais me fascina até os dias de hoje.

Para mim, a questão é que a reflexão antropológica é fundamental para a formação de professores, como bem pontuou Mafra (2007): enquanto a diversidade for uma questão para as sociedades humanas, haverá um espaço para a Antropologia. Ao lidar mais de perto com a formação de professores, pude perceber como havia uma necessidade de pensar tais questões, pois os futuros docentes chegavam aos bancos universitários com concepções arraigadas e estanques sobre o "outro", esse outro sendo o aluno. Algumas questões eram bastante próprias do universo discente; afirmações como “eles não querem nada", que, ao ser contrastada com a perspectiva de que a escola é, em verdade, um espaço de produção sociocultural, perdiam fôlego. Também eram recorrentes e persistentes posições etnocêntricas, que demandaram uma discussão mais aprofundada sobre o processo de construção social da diferença.

Mesmo dentro da rede tecnológica, mudei de campus (indo para a cidade de Floresta-PE) e depois de instituição (prestei um novo concurso para o Instituto Federal de Pernambuco no campus de Vitória de Santo Antão-PE), passando por diversos pontos do mesmo Estado, o que me levou a um confronto ainda mais decisivo com a diversidade cultural e suas implicações 
sobre o campo educacional. Questões como gênero, raça, violência, pobreza etc. emergiam em sala de aula, seja enquanto tema a ser debatido ou enquanto variável que motivava os mais diversos conflitos e dilemas, nos quais eu me situava como professor.

Nesse período resolvi prestar seleção de doutorado e, dentre as várias opções que tive, optei por ingressar em um Programa de Sociologia, o que não foi uma escolha fácil, tendo em vista meu fascínio pela Antropologia. Todavia, os caminhos da pesquisa e da trajetória pessoal possuem muitos imponderáveis, como demonstrado magistralmente no trabalho de Silva (2006), no meu caso, pesou o fato de fazer o doutorado na mesma disciplina que lecionava, no caso a Sociologia. De todo o modo, pelo meu tema, e pelo meu projeto de pesquisa, assumidamente etnográfico, foi-me indicada a orientação de um renomado Antropólogo no campo da Religião, o professor Roberto Motta, possivelmente o maior intelectual com o qual tive o prazer de conviver, e isso me deixou bastante à vontade, certamente minha tese sairia com traços fortemente antropológicos, além do mais, as fronteiras entre a Sociologia e a Antropologia sempre percebi como tênues, e mesmo ambivalentes, como nos indica Freyre (1968). O fato é que, na banca final de defesa de minha tese, havia mais antropólogos que sociólogos.

Nesse período, começo a realizar alguns paralelos no campo da Educação e da Antropologia, pensando principalmente Paulo Freire; para mim, restava a certeza incondicional de que Freire havia proposto um método antropológico de alfabetização, uma vez que a utilização de palavras geradoras pressupunha o conhecimento da realidade cultural do aluno. Passei a olhar Freire como o principal elo entre a Antropologia e a Educação naquele momento.

\section{Mudando os Ares... a Ida para a Educação}

Segui publicando na área de Religião e Educação, e data do meu segundo ano de tese a minha participação em um Grupo de Trabalho de Antropologia da Educação, durante a $27^{\circ}$ Reunião Brasileia de Antropologia, coordenado pelas professoras Neusa Gusmão (UNICAMP) e Janirza (Jana) Lima (FUNDAJ); saber da existência de tal discussão dentro da Associação Brasileira de Antropologia me encheu de esperanças de que seria possível mobilizar 
Antropólogos para o debate educacional, ainda que tivesse clareza dos limites impostos pelo campo acadêmico, que hierarquiza os temas mais e menos nobres de serem pesquisados (BOURDIEU, 2011).

Quando decidi enviar o trabalho para esse evento, que versava sobre uma interpretação da realidade escolar a partir do substrato teórico de Roberto DaMatta, quase concomitantemente decidi prestar concurso para a Universidade Federal de Alagoas (UFAL), e, apesar de haver vaga no mesmo edital para o Instituto de Ciências Sociais, optei por me submeter à vaga do Centro de Educação, que se destinava à Antropologia da Educação e à Prática de Ensino em Ciências Sociais.

Tendo sido aprovado no concurso em primeiro lugar, passei a ter um contato mais intenso com um curso com que até então não tinha proximidade: pedagogia. Para mim, foi uma experiência desafiadora; arriscaria dizer que, mais que lecionar para os cursos de formação de professores em exatas, pois, de fato, eu debatia naquele momento educação com especialistas no campo, mas que não entendiam muito bem a especificidade do que eu fazia. Não à toa, tornei-me "o antropólogo" dentro curso, ao passo que os demais professores eram apenas professores; eu certamente era um outsider.

Concordo com Gusmão (2006) ao indicar que o diálogo com a Educação, e mais ainda com o curso de Pedagogia, nem sempre é fácil para a Antropologia. Questões que parecem evidentes para um antropólogo não eram, por vezes, para um pedagogo e vice-versa. Falar em diversidade na educação era interpretado, quase inevitavelmente e sempre, como uma referência à educação inclusiva, não que esse não fosse um tema potencialmente do interesse da Antropologia, mas a compreensão de diversidade que eu tinha (e tenho) estava para além disso. Reside aí um ponto que merece destaque: a contribuição que a Antropologia pode trazer para a Educação por meio do alargamento do conceito de diversidade, ligando-o visceralmente à diversidade cultural, e, enquanto tal, permeava necessariamente todos os agentes envolvidos na prática educacional.

Outro conceito que a Antropologia se propõe alargar é o de Educação, muitas vezes reduzido à escolarização. Afora alguns poucos colegas, notadamente aqueles ligados aos Estudos Culturais, a maior parte não pensava 
educação para além dos muros da escola; todos os projetos de pesquisa em curso que havia entre meus pares naquele momento referiam-se à educação escolar, o que também era de meu interesse, mas não unicamente.

Passei a coordenar Grupos de Trabalho e a participar de Mesas Redondas em eventos diversos, como a Reunião de Antropologia do Mercosul, Reunião Equatorial de Antropologia/Encontro Norte-Nordeste de Antropólogos, Congresso Latino-Americano de Antropologia, Encontro Norte-Nordeste de Ciências Sociais, Reunião Brasileira de Antropologia, possuindo como parceiras mais constantes as professoras Neusa Gusmão (UNICAMP) e Sandra Tosta (PUC Minas), além de outros colegas, como Rodrigo Rosistolato (UFRJ), Ana Prado (UFRJ), Tânia Dauster (PUC Rio), Ceres Brum (UFSM), Maxim Repetto (UFRR), Bernadete Beserra (UFC), Marion Quadros (UFPE), Max Maranhão (UECE), Yvonne Maggie (UFRJ), Álamo Pimentel (UFAL), dentre outros, que, em sua maioria, são antropólogos vinculados a Faculdades de Educação, o que aponta para o lugar periférico que essa discussão ocupa nas Ciências Sociais. Também outros colegas fora do Brasil, como Ricardo Vieira (Portugal), Andrea Valvida (Chile), Maritza Diaz (Colômbia), Laura Cerletti (Argentina) e Maximiliano Rúa (Argentina), se mostraram como importantes interlocutores.

Os Grupos atraíram sempre um número bastante significativo de pesquisadores, tanto que, em 2013, criamos um novo grupo voltado para a discussão própria do Ensino de Antropologia; considerando a crescente demanda, sua primeira edição ocorreu junto à Reunião de Antropologia do Mercosul, em 2013, e a segunda junto à Reunião Brasileira de Antropologia, em 2014. Se havia uma marca nesses inúmeros grupos seria a hibridez, pois tanto congregavam pesquisadores com formação em educação, porém com uma reflexão desenvolvida a partir do substrato oferecido pela Antropologia, quanto antropólogos preocupados com a educação.

Em termos de temática, certamente o debate sobre a Educação Escolar Indígena apresentou uma preponderância inquestionável, o que reflete a agenda de pesquisa privilegiada no campo da Antropologia brasileira e latinoamericana. Se aceitarmos o critério que Bourdieu (2004) estabelece para medir o grau de autonomia de um campo, qual seja, a capacidade de refratar as influências externas, temos que a Antropologia da Educação é ainda um 
campo pouco autônomo, já que, passando em revista os papers apresentados nesses grupos por mim coordenados, percebo uma clara consonância com os campos hegemônicos na Antropologia.

A impressão que tenho é de que a Antropologia da Educação ainda é um campo em formação, cujo processo de legitimação, tanto na Antropologia quanto na Educação, ainda depende da mobilização e engajamento dos agentes no seu fomento, tarefa essa que tenho assumido para mim nesses anos. Considero que ainda não há clareza por parte de meus pares na Educação sobre o que faço, como se um Antropólogo no campo educacional fosse um anormal, nos termos postos por Foucault (2001); também não creio que os meus colegas antropólogos tenham uma visão menos obscura sobre o que realizo.

\section{Antropologia na Pós-Graduação em Educação}

Como os agentes no campo estão em constantes disputas, eu, enquanto tal, lancei mão das ferramentas que compreendi como necessárias para tanto, o que implicava, também, no caso brasileiro, no ingresso no Programa de PósGraduação. Afora a dimensão das disputas simbólicas, o fato é que, apesar da dificuldade apontada por vários alunos no processo de apreensão da disciplina no curso de Pedagogia, havia um interesse crescente de alunos na área, que almejavam realizar seus Trabalhos de Conclusão de Curso a partir de uma perspectiva antropológica, bem como cada vez mais alunos do curso de Ciências Sociais buscavam se aproximar do debate educacional.

Cheguei a desenvolver uma reflexão mais sistemática com dois alunos que acompanhei mais de perto no curso de Pedagogia sobre o processo de Ensinar e Aprender Antropologia (OLIVEIRA; NASCIMENTO; SANTOS, 2014), ambos foram monitores da disciplina na graduação e realizaram seus trabalhos finais nessa fronteira do saber.

A crescente demanda por parte dos alunos na graduação refletia o potencial que a disciplina de Antropologia poderia ter na formação docente, ainda que com uma carga horária bastante reduzida, no meu caso. Certa vez, ao realizar o balanço da disciplina, coisa que faço ao final de cada semestre, ouvi dos alunos que Antropologia da Educação tinha sido a disciplina mais 
prática que eles tinham tido naquele semestre, o que me surpreendeu, pois sempre percebi como uma disciplina teórica, aliás ela compunha os "fundamentos teóricos da educação", segundo a classificação do curso; mas, como bom antropólogo, instiguei-os para ir mais adiante e aí entendi o que queriam dizer, no fim das contas a Antropologia era a disciplina que mais se preocupava em falar da realidade cotidiana em sala de aula, havia na disciplina uma proposta implícita de romper com aquilo que Azanha (1992) denominou de "abstracionismo pedagógico", pois, parafraseando Mauss (2003), não me interessava o aluno em geral, mas o aluno tal e qual sala de aula. Segundo meus alunos, a Antropologia da Educação thes auxiliava na compreensão de outros temas no curso, em especial aqueles vinculados à discussão de currículo.

Havendo esse feedback na graduação, o certo é que o ingresso na pós implicaria não só na ampliação das possibilidades de pesquisa, como também traria a possibilidade de haver uma continuidade com relação ao que vinha se desenvolvendo. Concomitantemente a esse movimento criei um grupo de pesquisa, junto com outro colega recém-chegado, o professor Álamo Pimentel, que teria vindo para assumir as disciplinas de pesquisa educacional, porém, tendo uma profunda afinidade e conhecimento no campo da Antropologia, logo se torna meu parceiro; a jornada tornava-se menos solitária agora, o grupo absorveu uma significativa demanda, emergindo vários temas relevantes no campo da educação, destacando-se os estudos de gênero, relações étnico-raciais e a interface com a religião também. Como muito do que se discutia referia-se ao universo da educação infantil, logo também se percebeu a necessidade de discutir Antropologia da Criança.

Apesar da criação do grupo de pesquisa e da crescente adesão por parte dos alunos para meus pares, a Antropologia continuava a ser uma incógnita, tanto que em uma dada semana de apresentação de trabalhos acadêmicos uma das alunas do grupo, minha orientanda na época, ao apresentar a parte metodológica do seu trabalho, foi questionada pela avaliadora pelo fato de que não haveria estudos etnográficos em educação, mas apenas estudos "do tipo etnográfico", o que em minha opinião é apenas um subterfúgio para uma indefinição metodológica, e, mais que isso, que uma etnografia só poderia ser 
realizada após 5 anos de campo, o que me fez supor que nem as teses de doutorado em Antropologia poderiam ser etnográficas, dada o tempo máximo de conclusão (4 anos), o qual não é aproveitado integralmente em campo; este pequeno acontecimento, quase anedótico, indica as confusões ainda persistentes no processo de apropriação da Antropologia em Educação.

Na Pós-Graduação, toda essa demanda reprimida também apareceu, o que indica a significativa relevância para os Programas de Educação a existência do debate antropológico, pois mesmo aqueles que não possuíam como interesse realizar pesquisas na Antropologia da Educação procuravam minha disciplina, tanto para se aproximar de conceitos centrais dessa ciência, especialmente o de Cultura, muitas vezes acionado pelo campo educacional, porém poucas vezes delimitado com clareza, quanto das questões metodológicas, voltando aí um intenso debate nesse campo, quando nos referimos ao processo de apropriação da etnografia a educação. A grande questão para mim era demonstrar para os alunos primeiramente que não se trata de uma "técnica", no sentido de irmos aplicá-la e dela retirarmos dados, até porque os dados etnográficos não estão lá simplesmente, eles são construídos intersubjetivamente na relação entre pesquisador e pesquisado (OLIVEIRA, 2006), e também que não há uma separação entre teoria e método, de modo que há uma ligação profunda entre determinados conceitos e os paradigmas de pensamento ao qual se vinculam, ainda que o pesquisador, via de regra, não trabalhe com um único paradigma de pensamento (OLIVEIRA, 1988).

A busca pelo estudo da etnografia envolveu, portanto, mestrandos e doutorandos com as mais diversas demandas, incluindo aqueles de domínio conexo oriundos de outros Programas, temas de pesquisa como políticas públicas, tecnologias da informação e comunicação, educação de jovens e adultos, processo de ensino e aprendizagem, currículo etc., sempre apareciam em sala de aula. Minha preocupação primordial era de me posicionar contra a ideia de que em educação só é possível realizar estudos “do tipo etnográfico”, afirmando que, sim, era possível realizar etnografias nas pesquisas educacionais; para além da sala de aula, tive a oportunidade de 
expor meu ponto de vista em congressos diversos e em algumas publicações (OLIVEIRA, 2013a, 2013b, 2013d).

No caso específico das primeiras orientações que tive mais voltadas para a esse campo, emergiram temas clássicos, claro que nem todos que me procuravam estavam interessados em Antropologia; como único cientista social do programa, havia também uma demanda no âmbito da Sociologia da Educação, e mesmo referente ao Ensino de Ciências Sociais, tema de crescente interesse dos egressos da licenciatura nessa área, e ao qual tenho também me dedicado.

O fato é que dessas primeiras orientações duas possuíam claramente um caráter antropológico: uma primeira referia-se às diversas concepções de educação escolar indígena entre os professores de uma dada aldeia. A orientanda em questão já possuía uma ligação com o grupo, tendo-o pesquisado em sua graduação, mas sob outro viés. Como boa parte dos etnólogos indígenas, ela tinha como marca a busca por uma vivência intensiva de campo; ironicamente em sua qualificação, um dos avaliadores, pesquisador na área de educação indígena, a cobrou que ela trouxesse mais "teóricos da educação" e menos antropologia. Ora, esse pedido só reforça minha compreensão acerca do processo de construção da legitimação da disciplina no campo educacional, pois esses tais “teóricos da educação" também provinham de campos disciplinares específicos, tal qual Psicologia da Educação, Sociologia da Educação, História da Educação; tratava-se apenas de perceber algumas disciplinas como mais e outras como menos legítimas para se debater Educação, e nessa interpretação a Antropologia estaria no segundo polo.

Outro trabalho que abertamente percorria esse percurso referia-se ao estudo das crianças de candomblé na escola, mais especificamente sobre a (in)visibilização de suas identidades religiosas no contexto escolar. 0 aluno que se propôs desenvolver essa pesquisa pertence ao candomblé, e o exercício antropológico de familiarizar o exótico e estranhar o familiar, mesmo reconhecendo os limites deste (DAMATTA, 1978), mostrou-se fundamental nesse caso. Tenho para mim que, em verdade, esse é um exercício extremamente necessário para todas as pesquisas em educação, 
tendo em vista que, em sua maioria, aqueles que ingressam em mestrados e doutorados em educação são agentes envolvidos no campo educacional: professores, gestores, alunos recém-egressos de licenciaturas etc. Acredito, desse modo, que as reflexões epistemológicas que vêm sendo desenvolvidas na Antropologia nas últimas décadas podem trazer um ganho substancial para as diversas pesquisas em educação, por mais que não dialoguem com questões tão “claramente antropológicas”.

Afora esta experiência, também puder lecionar uma disciplina intitulada “Educação e Diversidade" junto a um curso de especialização em Antropologia, que foi ofertado pelo Instituto de Ciências Sociais da UFAL. Fiz isso em parceria com a professor Nádia Meinerz, tendo orientado ainda dois trabalhos que também se propuseram a desenvolver um rico diálogo entre essas áreas do saber.

Ainda que seja um entusiasta da Antropologia na Educação, não acredito que sua presença pontual, seja em nível de graduação ou de pós-graduação, possa, por si só, alterar completamente o cenário da educação em termos de pesquisa (OLIVEIRA, 2012), porém acredito no seu impacto em termos epistêmicos, metodológicos e cognitivo, uma vez que o contato com a Antropologia possibilita a elaboração de uma nova percepção sobre a educação.

\section{Considerações Finais}

De fato, perceber a biografia como uma narrativa coerente, marcada por acontecimentos ordenados é uma ilusão (BOURDIEU, 1996); há deslocamentos e descontinuidades que marcam a trajetória dos sujeitos, e que, no caso de uma carreira acadêmica, evidencia-se pela mudança de foco que ocorre por vezes, o que foi meu caso, ainda que em nenhum momento eu tenha abandonado completamente a religião como objeto de investigação. Como nos indica Gusmão em entrevista recente (GUSMÃO; OLIVEIRA, 2013), para a maioria dos estudos antropológicos a educação não é algo central, mas o trabalho de campo é que se mostra capaz de produzir um olhar capaz de captar as problemáticas relativas à educação. 
Ter sido professor da Educação Básica certamente pesou significativamente sobre a forma como percebi a relevância de produzir estudos antropológicos em educação, e no meu entender não há como avançarmos no campo sem pensar a produção de conhecimento antropológico no campo educacional. Isto pode parecer evidente, todavia muito do que tem se afirmado como estudos desenvolvidos na interface entre a Educação e a Antropologia, em verdade, não dialoga com conceitos-chave dessa ciência (OLIVEIRA, 2011).

No final das contas, muito do meu olhar se deve à transformação de minha condição de "nativo" para pesquisador, o que nem sempre (quase nunca) é uma tarefa fácil. Acrescento ainda que a transformação de minha percepção da realidade e minha crescente aproximação com outros temas se move, em grande medida, pela renovação intelectual que o fazer docente me proporciona, especialmente por meio das orientações.

Mais recentemente realizei aquela que espero ser minha última mudança institucional: encontro-me na Universidade Federal de Santa Catarina, não mais vinculado a um Centro de Educação, mas, sim, ao Centro de Filosofia e Ciências Humanas, ainda que meu concurso tenha sido uma vaga especificamente destinada à área de Educação junto ao curso de Ciências Sociais. Estou tendo uma experiência interessante com um diálogo profícuo com alguns pares, especialmente as professoras Antonella Tassinari, que dialoga com a Antropologia da Educação por meio da Antropologia da Criança e da Educação Indígena, e Miriam Grossi, que têm coordenado um projeto de extensão sobre Gênero e Diversidade nas Escolas, no qual tenho me engajado, ambas integram o Departamento de Antropologia da UFSC. Interessante destacar o fato de ter agora duas colegas antropólogas que debatem educação, pois isso reflete as mudanças que estão em curso em campo, com uma presença mais incisiva de cientistas sociais, de modo geral, e de antropólogos, de forma particular, na investigação educacional.

Por fim, ressalto que o advento de uma série de questões no campo das políticas públicas - como a lei 10.639/03, que torna obrigatório o ensino de história e cultura afro-brasileira e africana nas escolas, seguida pela lei 11.645/08, que inclui a questão indígena; a criação da Secretaria de Educação 
Continuada, Alfabetização e Diversidade (SECADI), em 2004, que apresentaria como intuito a articulação, dentre outras questões, o tema da diversidade nas políticas educacionais; e as ações afirmativas - tem pautado uma agenda de discussões em relação à qual os antropólogos não podem se furtar de se posicionar.

O campo da Antropologia da Educação, enquanto aquele que ainda está se formando, demanda um engajamento político e intelectual por parte daqueles que acreditam nas possibilidades abertas por essa interface, sejam eles antropólogos ou não.

\section{Referências}

ANDRÉ, Marli. Etnografia da prática escolar. Campinas: Papirus, 1995.

AZANHA, José Mário Pires. Uma ideia de pesquisa educacional. São Paulo: Edusp, 1992.

BOURDIEU, Pierre. Homo academicus. Florianópolis: EDUSFC, 2011.

- Os usos sociais da ciência: por uma sociologia clínica do campo científico. São Paulo: Editora UNESP, 2004.

. Razões práticas. Campinas: Papirus, 1996.

DAMATTA, Roberto. O ofício do etnólogo, ou como ter 'Anthropological Blues'. In: NUNES, Edson de Oliveira (Org.). A aventura sociológica: objetividade, paixão, improviso e método na pesquisa social. Rio de Janeiro: Zahar Editores, 1978. p. 23-35.

DAUSTER, Tânia. Um saber de fronteira - entre a antropologia e a educação. In: _. Antropologia e educação: um saber de fronteira. Rio de Janeiro: Forma \& Ação, 2007. p. 13-35.

FOUCAULT, Michel. Os anormais. São Paulo: Martins Fontes, 2001.

FREYRE, Gilberto. Como e porque sou e não sou sociólogo. Brasília: Ed. Universidade de Brasília, 1968.

GEERTZ, Clifford. Nova luz sob a antropologia. Rio de Janeiro: Jorge Zahar, 2001.

GUSMÃO, Neusa Maria. Antropologia e educação: história e trajetos. In: GROSSI, Mirian Pillar; TASSINARI, Antonella; RIAL, Carmen. (Org.). Ensino de antropologia no Brasil: formação, práticas disciplinares e além-fronteiras. Blumenau: Nova Letra, 2006, p. 299-331.

Antropologia e educação: origens de um diálogo. Cadernos CEDES, Campinas, v. 18, n. 43, p. 8-25, dez. 1997. 
. Entrelugares: antropologia e educação no Brasil. Revista Educação, Santa Maria, v. 34, n. 1, p. 29-46, 2009.

- Os desafios da diversidade na escola. In: GUSMÃO, Neusa Maria (Org.). Diversidade, cultura e educação: olhares cruzados. São Paulo: Biruta, 2003. p. 83-105.

GUSMÃO, Neusa Maria; OLIVEIRA, Amurabi. Antropologia e/da educação no Brasil: entrevista com Neusa Gusmão. Cadernos de Campo, São Paulo, n. 22, p. 147-160, 2013.

MAFRA, Clara. Um mundo sem antropologia. Antropolítica, Rio de Janeiro, v. 22, p. 151-167, 2007.

MAUSS, Marcel. Sociologia e antropologia. São Paulo: Cosac \& Naify, 2003.

MORAES, Amaury Cesar. Licenciatura em ciências sociais e ensino de sociologia: entre o balanço e o relato. Tempo Social, São Paulo, v. 15, n. 1, p. 5-20, 2003.

NOGUEIRA, Maria Alice; CANAAN, Maria Gadoni. Os iniciados: os bolsistas de Iniciação Científica e suas trajetórias acadêmicas. Tomo, São Cristóvão, v. 15, p. 41-70, 2009.

OLIVEIRA, Amurabi. A antropologia dos não antropólogos e outras questões etnocêntricas. Revista Anthropológicas, Recife, v. 22, n. 1, p. 101-123, 2011.

- Algumas pistas (e armadilhas) na utilização da etnografia na educação. Educação em Foco, Maringá, v. 16, n. 22, p. 163-183, 2013a.

Antropologia e antropólogos, educação e educadores: o lugar do ensino de antropologia na formação docente. Percursos, Florianópolis, v. 13, p. 120-132, 2012.

- Etnografia e pesquisa educacional: por uma descrição densa da educação. Educacao Unisinos, São Leopoldo, v. 17, n. 3, p. 271-280, $2013 \mathrm{~b}$.

- O lugar da antropologia na formação docente: um olhar a partir das escolas normais. Pro-Posições, Campinas, v. 24, n. 2, p. 27-40, $2013 \mathrm{c}$.

- Por que etnografia no sentido estrito e não estudos do tipo etnográfico em educação? Revista FAEEBA, Salvador, v. 22, n. 40, p. 69-82, 2013d.

OLIVEIRA, Amurabi; NASCIMENTO, Fernanda; SANTOS, Jhones. 0 ensino e seus espelhos: a formação antropológica para não antropólogos. Cadernos da Pedagogia, São Carlos, v. 7, n. 14, p. 114-125, 2014.

OLIVEIRA, Roberto Cardoso de. O trabalho do antropólogo. São Paulo: Ed. UNESP, 2006. 1988.

Sobre o pensamento antropológico. Rio de Janeiro: Tempo Brasileiro, 
PEIRANO, Mariza. The anthropology of anthropology: the brazilian case. 1981. Tese (Doutorado) - Departament of Anthropology, Harvard University, Cambridge, 1981.

PEREIRA, Júlio Emílio Diniz. As licenciaturas e as novas políticas educacionais para a formação docente. Educação \& Sociedade, Campinas, v. 20, n. 68, p. 109-125, 1999.

ROCHA, Gilmar; TOSTA, Sandra Pereira. Antropologia \& Educação. Belo Horizonte: Autêntica, 2008.

SILVA, Vagner Gonçalves. O antropólogo e sua magia. São Paulo: EDUSP, 2006.

VALENTE, Ana Lúcia E. F. Usos e abusos da antropologia na pesquisa educacional. Pro-Posições, Campinas, v. 7, n. 20, p. 54-64, 1996.

Recebido em: 30/11/2014

Aceito em: 07/07/2015 